\title{
Quality of life, long-term survivors and long-term outcome from the ABC-02 study
}

John Bridgewater ${ }^{*},{ }^{1}$ Andre Lopes ${ }^{2}$, Daniel Palmer ${ }^{3}$, David Cunningham ${ }^{4}$, Alan Anthoney ${ }^{5}$, Anthony Maraveyas $^{6}$, Srinivasan Madhusudan ${ }^{7}$, Tim Iveson ${ }^{8}$, Juan Valle ${ }^{9,11}$ and Harpreet Wasan ${ }^{10,11}$ on behalf of the $\mathrm{ABC}-02$ investigators $^{12}$

${ }^{1}$ UCL Cancer Institute, UCL, London WC1E 6DD, UK; ${ }^{2}$ UCL and CRUK Clinical Trials Centre, UCL, London W1T 4TJ, UK; ${ }^{3}$ Institute of Translational Medicine, University of Liverpool, Liverpool L69 3BX, UK; ${ }^{4}$ Department of Medicine, Royal Marsden Hospital, Sutton SM2 5PT, UK; ${ }^{5}$ Department of Oncology, St. James's Hospital, Leeds LS9 7TF, UK; ${ }^{6}$ Department of Oncology, Castle Hill Hospital, Hull HU16 5JQ, UK; ${ }^{7}$ Department of Oncology, Nottingham University Hospitals, Nottingham NG7 2UH, UK; ${ }^{8}$ Department of Oncology, Southampton University Hospitals, Southampton SO16 6YD, UK; ${ }^{9}$ The University of Manchester, Manchester M20 4BX, UK and ${ }^{10}$ Hammersmith Hospital, London W12 OHS, UK

Background: The ABC-02 (Advanced Biliary Tract Cancer) study established cisplatin and gemcitabine (CisGem) as the standard first-line chemotherapy for patients with locally advanced or metastatic biliary tract cancer (BTC). We examine quality of life (QoL), describe the long-term survivors and provide a long-term outcome.

Methods: A total of 410 BTC patients were randomised to receive either CisGem or gemcitabine alone (Gem); 324 patients consented to complete EORTC QLQ-C30 and EORTC QLQ-PAN26 QoL questionnaires; 268 (83\%) patients returned at least one QoL questionnaire (134 in each arm). Long-term survivors were defined as those surviving over 2 years and we performed a final analysis of the primary outcome; overall survival (OS).

Results: Most QoL scales showed a trend favouring the combined CisGem arm, including functional and symptomatic scales, although the differences were not statistically significant. Forty-five (11\%)) patients survived at least 2 years (34 received CisGem and $11 \mathrm{Gem}$ ) and 21 (5\%) 3 years or more ( 14 received CisGem and $7 \mathrm{Gem}$ ). After a median follow-up of 9.2 months and 398 deaths, the median OS was 11.7 months for CisGem and 8.1 months for Gem (hazard ratio $(H R)=0.65,95 \%$ Cl: 0.53-0.79, $P<0.001$ ).

Conclusions: The survival advantage of CisGem compared to Gem was not associated with an improvement or deterioration of QoL. Long-term survivors were more likely to have received CisGem and the long-term OS is identical to that previously described.

Biliary tract cancers (including cholangiocarcinoma and cancers of the gallbladder and ampulla of Vater, BTC) are uncommon cancers with a poor prognosis (de Groen et al, 1999). The standard of care for advanced biliary tract cancers $(\mathrm{ABC})$ was established following publication of the ABC-02 (Advanced Biliary Tract Cancer) trial, which demonstrated that the addition of cisplatin to gemcitabine (CisGem vs Gem) significantly improved overall survival (OS) and progression-free survival by 3.6 months and 3 months, respectively compared to gem alone (Valle et al, 2010). These data were supported by a similar Japanese phase 2 study (Okusaka et al, 2010) and a subsequent meta-analysis of these data with ABC-02 (Valle et al, 2013).

Maintaining quality of life is a key goal of treatment and impacts on the decision patients make with respect to treatment.

*Correspondence: Professor J Bridgewater; E-mail: j.bridgewater@ucl.ac.uk

${ }^{11}$ Joint senior authors.

${ }^{12}$ The recruiting sites and principal investigators in the ABC-02 study are listed at the end of the paper.

Received 4 November 2015; revised 12 January 2016; accepted 16 February 2016

(c) 2016 Cancer Research UK. All rights reserved 0007 - 0920/16 
Table 1. Cox regression analysis for the association between each QoL response at baseline and overall survival

\begin{tabular}{|c|c|c|c|c|c|c|}
\hline \multirow[b]{2}{*}{ QoL response ${ }^{a}$} & \multicolumn{2}{|c|}{ QoL scores ${ }^{b}$} & \multicolumn{2}{|c|}{$\begin{array}{l}\text { Overall survival univariate } \\
\text { cox models }{ }^{c}\end{array}$} & \multicolumn{2}{|c|}{$\begin{array}{l}\text { Overall survival multivariate } \\
\text { cox models } s^{c, d}\end{array}$} \\
\hline & $\begin{array}{c}\leqslant 50 \text { score } \\
N(\%)^{\mathrm{e}}\end{array}$ & $\begin{array}{c}>50 \text { score } \\
N(\%)\end{array}$ & $\begin{array}{c}\mathrm{HR}(99 \% \mathrm{Cl})>50 \text { score } \\
\text { vs } \leqslant 50 \text { score }\end{array}$ & $P$-value & $\begin{array}{c}\mathrm{HR}(99 \% \mathrm{Cl})>50 \text { score } \\
\text { vs } \leqslant 50 \text { score }\end{array}$ & $P$-value \\
\hline Global health & $98(30 \%)$ & $157(48 \%)$ & $0.59(0.42-0.83)$ & $<0.001$ & $0.63(0.44-0.91)$ & 0.001 \\
\hline Social functioning & 78 (24\%) & $176(54 \%)$ & $0.78(0.55-1.12)$ & 0.08 & $0.93(0.62-1.40)$ & 0.64 \\
\hline Emotional functioning & $61(19 \%)$ & $195(60 \%)$ & $0.87(0.59-1.27)$ & 0.34 & $0.91(0.60-1.38)$ & 0.57 \\
\hline Role functioning & $97(30 \%)$ & $160(49 \%)$ & $0.67(0.48-0.94)$ & 0.002 & $0.77(0.53-1.11)$ & 0.06 \\
\hline Physical functioning & $46(14 \%)$ & $213(66 \%)$ & $0.46(0.30-0.70)$ & $<0.001$ & $0.56(0.34-0.92)$ & 0.003 \\
\hline Appetite loss & $192(59 \%)$ & $65(20 \%)$ & $1.60(1.10-2.34)$ & 0.001 & $1.42(0.96-2.10)$ & 0.02 \\
\hline Financial difficulties & $210(65 \%)$ & $44(14 \%)$ & $0.90(0.58-1.39)$ & 0.54 & $0.91(0.57-1.45)$ & 0.59 \\
\hline Nausea and vomiting & 244 (75\%) & $15(5 \%)$ & $1.89(0.93-3.86)$ & 0.02 & $1.98(0.94-4.17)$ & 0.02 \\
\hline Constipation & $217(67 \%)$ & $38(12 \%)$ & $1.40(0.88-2.23)$ & 0.06 & $1.24(0.71-2.14)$ & 0.32 \\
\hline Diarrhoea & $236(73 \%)$ & $17(5 \%)$ & $0.95(0.50-1.82)$ & 0.84 & $0.94(0.48-1.84)$ & 0.80 \\
\hline Dyspnoea & $231(71 \%)$ & $27(8 \%)$ & $1.21(0.71-2.08)$ & 0.36 & $1.23(0.70-2.14)$ & 0.34 \\
\hline Satisfaction with health care & $48(15 \%)$ & $204(63 \%)$ & $1.15(0.75-1.76)$ & 0.40 & $1.15(0.74-1.80)$ & 0.41 \\
\hline Sexual functioning & $102(31 \%)$ & $114(35 \%)$ & $0.67(0.47-0.96)$ & 0.005 & $0.69(0.46-1.02)$ & 0.01 \\
\hline Digestive symptoms & $213(66 \%)$ & 43 (13\%) & $1.67(1.08-2.59)$ & 0.003 & $1.42(0.90-2.25)$ & 0.05 \\
\hline Hepatic & 245 (76\%) & $11(3 \%)$ & $1.30(0.58-2.90)$ & 0.40 & $1.07(0.46-2.47)$ & 0.84 \\
\hline Pancreatic pain & 199 (61\%) & $58(18 \%)$ & $1.51(1.02-2.25)$ & 0.007 & $1.39(0.90-2.15)$ & 0.05 \\
\hline Body image & $220(68 \%)$ & $35(11 \%)$ & $1.14(0.71-1.82)$ & 0.48 & $1.05(0.65-1.72)$ & 0.78 \\
\hline Altered bowel habit & $226(70 \%)$ & $29(9 \%)$ & $1.05(0.63-1.75)$ & 0.80 & $1.04(0.61-1.77)$ & 0.85 \\
\hline
\end{tabular}

Of particular concern for the $\mathrm{ABC}-02$ study was the potential impact of cisplatin-related fatigue, which numerically increased in the $\mathrm{ABC}-01$ study, the randomised phase 2 study that preceded ABC-02 (Valle et al, 2009). Additionally, we wished to document the global impact that any change in episodes of biliary sepsis, a difficult and common problem in BTCs, may have had.

We report quality of life in the ABC-02 study. Additionally we were interested in factors that defined long-term survivors, as we noted that, unlike historical data and clinical experience, there were a number of long-term survivors. We took the opportunity to reanalyse the primary outcome of the ABC-02 study; OS.

\section{METHODS AND METHODS}

Patients. A total of 324 patients asked to complete quality of life (QoL) questionnaires as part of the ABC-02 study. The 86 patients enrolled in the $\mathrm{ABC}-01$ study who contributed to the efficacy outcome of the combined $\mathrm{ABC}-01$ and $\mathrm{ABC}-02$ cohort did not complete QoL as this was not part of the randomised phase 2 protocol. Patients had a histopathological or cytological diagnosis of non-resectable, recurrent or metastatic biliary tract carcinoma (intra- or extra-hepatic cholangiocarcinoma), gallbladder or ampullary carcinoma; were aged $\geqslant 18$ years; had an estimated life expectancy $>3$ months; ECOG performance status $0-2$; and adequate haematological, renal and liver function.
Treatment. Patients were treated as described previously (Valle et al, 2010). Supportive medications such as anti-emetics were not proscribed and were given at the investigators discretion.

Quality of life. All patients were asked to complete the selfcompletion EORTC Quality of Life Questionnaire-Cancer 30 (EORTC QLQ-C30; Aaronson et al, 1993) and EORTC Quality of Life Questionnaire-Pancreatic Cancer 26 (EORTC QLQ-PAN26; Fitzsimmons et al, 1999), though this was optional. Quality of life was assessed at baseline, 12 weeks into treatment, one month after the completion of treatment, and 3 and 6 months after the 1 month assessment.

Statistical methods. We used the Pearson $\chi 2$ test and a nonparametric test for trend across ordered groups to assess each baseline characteristic (sex, age, disease status, primary site, histology, ECOG performance status and prior therapy) and treatment for any difference and trend over survival time, respectively. We categorised age into three age groups (23-60, 60-70 and 70-84 years), maintaining a large number of patients in each group and using clinically meaningful age boundaries. We used Kaplan-Meier curves and Cox proportional hazards regression to estimate survival and the hazard ratio (HR) for OS among all patients.

The association between baseline QoL responses and OS was done by categorising the QoL responses (initially on the $0-100$ continuous scale) into low scores ( $\leqslant 50$ score) or high scores $(>50$ 
score). High scores indicate good QoL for functional responses (e.g. physical functioning), but poor QoL for symptomatic responses (e.g. pain). The aim of the analysis is to assess whether

A

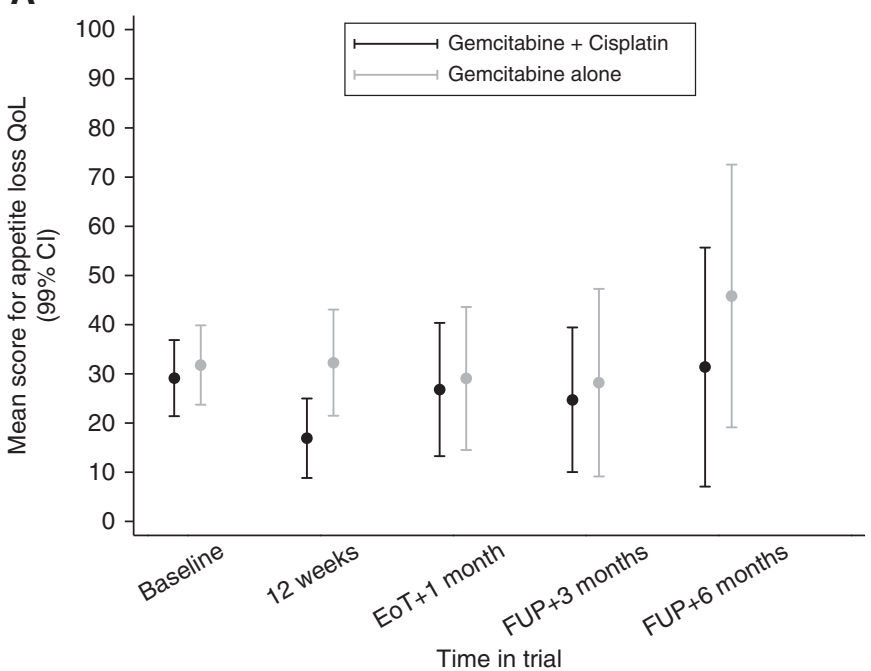

B

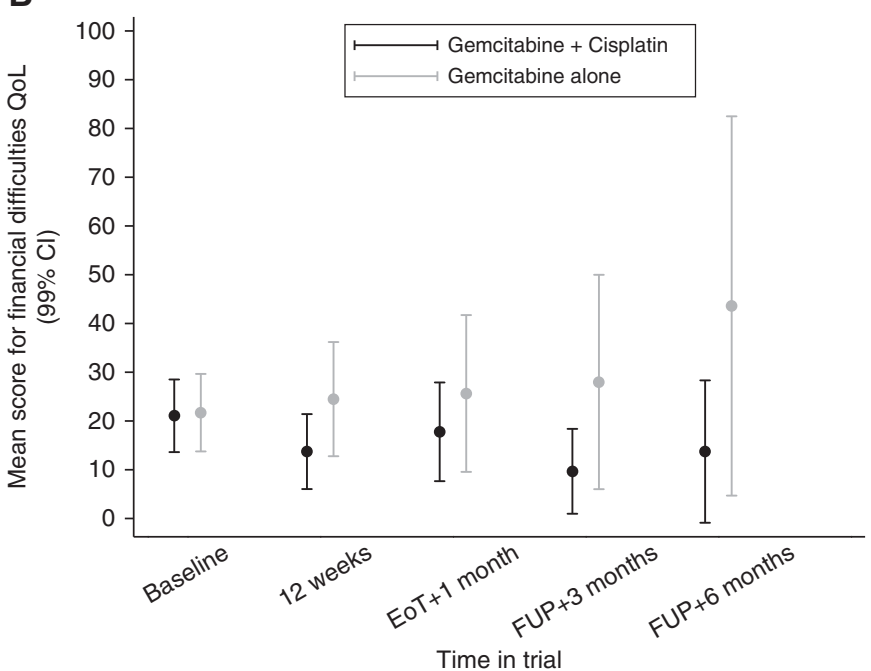

C

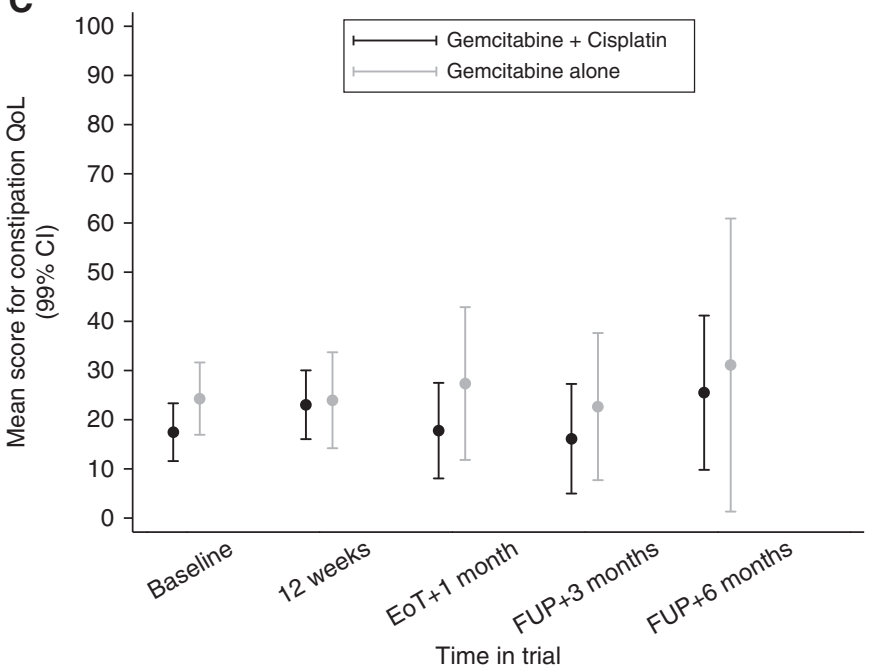

having a bad quality of life at baseline is associated with risk of death, and the results suggest that this is the case for some of the scales. We reported univariate and multivariate OS cox model
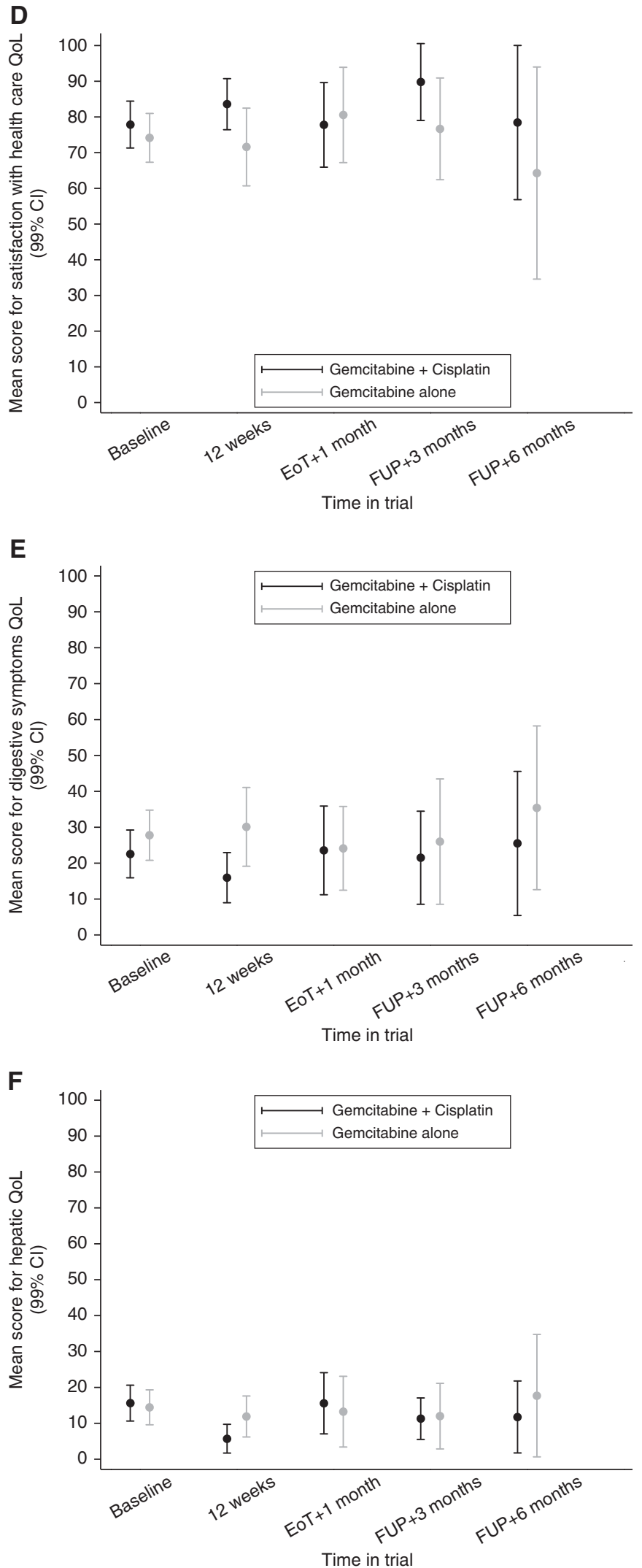

Figure 1. Quality of life across the five measurable time points for six $\mathrm{Q} o \mathrm{~L}$ scales. For each score the mean quality of life is provided with its $95 \%$ confidence interval. (A-F) Represent appetite loss, financial difficulties, constipation, satisfaction with health care, digestive symptoms and hepatic symptoms, respectively. 
Table 2. Treatment difference in quality of life at 12 weeks, adjusting for quality of life at baseline (analysis of covariance)

\begin{tabular}{|c|c|c|c|c|}
\hline \multirow[b]{2}{*}{ QoL response ${ }^{b}$} & \multicolumn{2}{|c|}{$\begin{array}{l}\text { Models adjusting for } \\
\text { baseline quality of life }\end{array}$} & \multicolumn{2}{|c|}{$\begin{array}{l}\text { Models adjusting for baseline quality of life } \\
\text { and baseline characteristics }{ }^{a}\end{array}$} \\
\hline & $\begin{array}{c}\text { Treatment mean difference }^{c} \\
\text { in quality of life at } \\
12 \text { weeks }^{d}(99 \% \mathrm{Cl})\end{array}$ & $P$-value & $\begin{array}{c}\text { Treatment mean difference }^{c} \\
\text { in quality of life at } \\
12 \text { weeks }^{d}(99 \% \mathrm{Cl})\end{array}$ & $P$-value ${ }^{\mathrm{e}}$ \\
\hline \multicolumn{5}{|l|}{ Global health status } \\
\hline Global health & $6.9(-2.5$ to +16.3$)$ & 0.06 & $5.9(-4.0$ to +15.8$)$ & 0.12 \\
\hline \multicolumn{5}{|l|}{ Functional scale } \\
\hline $\begin{array}{l}\text { Social functioning } \\
\text { Emotional functioning } \\
\text { Cognitive functioning } \\
\text { Role functioning } \\
\text { Physical functioning }\end{array}$ & $\begin{aligned} & 9.6(-2.2 \text { to }+21.4) \\
& 3.3(-6.5 \text { to }+13.2) \\
& 2.4(-5.9 \text { to }+10.7) \\
- & 0.2(-11.4 \text { to }+11.0) \\
- & 0.4(-7.9 \text { to }+7.1)\end{aligned}$ & $\begin{array}{l}0.04 \\
0.38 \\
0.45 \\
0.96 \\
0.88\end{array}$ & $\begin{array}{l}8.3(-4.0 \text { to }+20.6) \\
2.3(-8.0 \text { to }+12.7) \\
2.8(-5.8 \text { to }+11.3) \\
0.8(-10.8 \text { to }+12.4) \\
-1.1(-9.0 \text { to }+6.8)\end{array}$ & $\begin{array}{l}0.08 \\
0.56 \\
0.40 \\
0.86 \\
0.73\end{array}$ \\
\hline \multicolumn{5}{|l|}{ Symptom scale } \\
\hline $\begin{array}{l}\text { Appetite loss } \\
\text { Financial difficulties } \\
\text { Nausea and vomiting } \\
\text { Pain } \\
\text { Insomnia } \\
\text { Fatigue } \\
\text { Constipation } \\
\text { Diarrhoea } \\
\text { Dyspnoea }\end{array}$ & $\begin{array}{l}-15.7(-27.8 \text { to }-3.5) \\
-11.6(-24.6 \text { to }+1.3) \\
-5.4(-13.2 \text { to }+2.4) \\
-4.8(-15.2 \text { to }+5.6) \\
-4.5(-16.4 \text { to }+7.4) \\
-3.9(-14.0 \text { to }+6.3) \\
-1.1(-13.2 \text { to }+11.0) \\
-0.2(-9.6 \text { to }+9.2) \\
4.8(-6.6 \text { to }+16.2)\end{array}$ & $\begin{array}{l}0.001 \\
0.02 \\
0.07 \\
0.23 \\
0.33 \\
0.32 \\
0.81 \\
0.95 \\
0.27\end{array}$ & $\begin{array}{r}-13.2(-25.8 \text { to }-0.55) \\
-11.7(-25.0 \text { to }+1.5) \\
-3.0(-10.8 \text { to }+4.7) \\
-3.7(-14.5 \text { to }+7.1) \\
-4.9(-17.4 \text { to }+7.7) \\
-3.5(-14.2 \text { to }+7.3) \\
0.37(-11.9 \text { to }+12.7) \\
-0.02(-9.8 \text { to }+9.8) \\
5.2(-6.7 \text { to }+17.1)\end{array}$ & $\begin{array}{l}0.007 \\
0.02 \\
0.31 \\
0.37 \\
0.31 \\
0.40 \\
0.94 \\
0.99 \\
0.25\end{array}$ \\
\hline \multicolumn{5}{|l|}{ Biliary tract cancer-specific } \\
\hline $\begin{array}{l}\text { Satisfaction with health care } \\
\text { Sexual functioning } \\
\text { Digestive symptoms } \\
\text { Hepatic } \\
\text { Pancreatic pain } \\
\text { Body image } \\
\text { Altered bowel habit }\end{array}$ & $\begin{aligned} & 12.1(-0.2 \text { to }+24.5) \\
&-4.7(-22.0 \text { to }+12.6) \\
&-14.1(-25.7 \text { to }-2.5) \\
&-5.6(-12.1 \text { to }+0.9) \\
&-3.9(-12.1 \text { to }+4.3) \\
&-3.6(-15.8 \text { to }+8.7) \\
&-0.7(-11.0 \text { to }+9.6)\end{aligned}$ & $\begin{array}{l}0.01 \\
0.48 \\
0.002 \\
0.03 \\
0.22 \\
0.45 \\
0.86\end{array}$ & $\begin{aligned} & 11.1(-1.6 \text { to }+23.8) \\
&-7.2(-25.5 \text { to }+11.0) \\
&-13.4(-25.7 \text { to }-0.98) \\
&-5.3(-12.1 \text { to }+1.5) \\
&-3.5(-12.0 \text { to }+4.9) \\
&-2.0(-14.7 \text { to }+10.8) \\
&-1.7(-12.6 \text { to }+9.3)\end{aligned}$ & $\begin{array}{l}0.02 \\
0.30 \\
0.006 \\
0.04 \\
0.28 \\
0.69 \\
0.69\end{array}$ \\
\hline \multicolumn{5}{|c|}{ 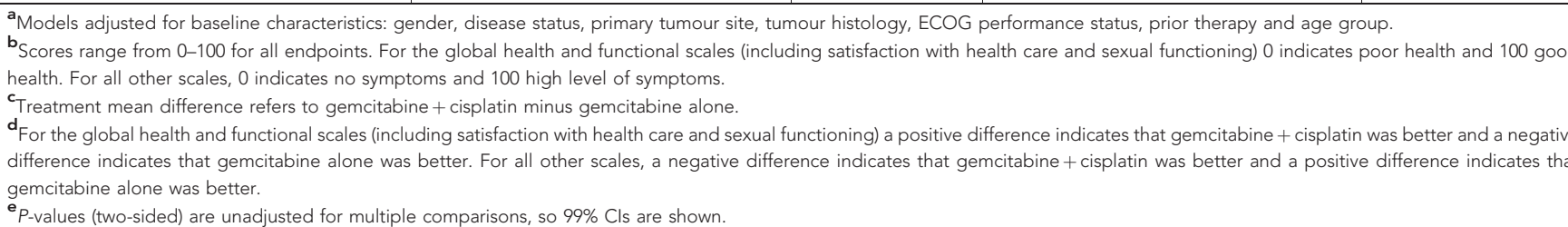 } \\
\hline
\end{tabular}

results using 50\% cut-offs as suggested by Sloan et al, 2012. CisGem was compared with Gem in terms of QoL responses at 12 weeks, adjusting for baseline values using ANCOVA (analysis of covariance), which is used to evaluate QoL at 12 months and is meaningful as it represents the median survival point.

Random intercept-slope models are fitted in order to take into account the repeated-measures nature of the QoL data. A separate model is fitted for each QoL subscale (response variable). These are two-level models with level 1 being the series of measurements taken over time within each patient and level 2 being the patient unit (cluster level). Random intercept-slope models include treatment group and number of days in each visit for each patient as fixed-effects covariates. We extended these intercept-slope models by including baseline characteristics as fixed-effects covariates: gender, disease status, primary tumour site, tumour histology, ECOG performance status, prior therapy and age group. We reported $99 \%$ CI for analysis of covariance and random intercept-slope models due to multiple testing.

\section{RESULTS}

Quality of life. A total of 268 (83\%) patients returned at least one QoL form (134 in each arm), though only 259 (80\%) returned the baseline form and 134 (41\%) of the patients returned the QoL form at 12 weeks (Supplementary Table S1). Missing data due to deaths and due to other causes are similar between treatment groups, with a slightly higher percentage of missing data due to deaths in the Gemcitabine arm. Only 11 (3\%) patients returned all five forms.

Table 1 shows the association between QoL scores and survival. A better survival outcome seems to be related with higher score levels in global health (HR 0.63, 99\% CI: $0.44-0.91, P=0.001$ ), role functioning (HR 0.77, 99\% CI: 0.53-1.11, $P=0.06$ ), physical functioning (HR 0.56, 99\% CI: $0.34-0.92, P=0.003$ ) and sexual functioning (HR 0.69, 99\% CI: $0.46-1.02, P=0.01$ ) at baseline. A worst survival experience seem to be associated with higher baseline score levels in the scales related with appetite loss (HR 1.42, 99\% CI: 0.96-2.10, $P=0.02$ ), nausea and vomiting (HR 1.98, 99\% CI: $0.94-4.17, P=0.02$ ), pain (HR $1.50,99 \%$ CI: $0.94-2.38, P=0.02$ ), digestive symptoms (HR 1.42, 99\% CI: $0.90-2.25, P=0.05)$ and pancreatic pain (HR 1.39, 99\% CI: $0.90-2.15, P=0.05)$. Supplementary Figure S1A and B show Kaplan-Meier plots for survival outcomes amongst patients who scored high and low in the global health functioning and physical functioning scales, respectively.

Treatment mean differences in the QoL scales at 12 weeks adjusted for baseline (ANCOVA analysis) are presented in Figure 1 and Table 2. The ANCOVA results imply a difference not statistically significant in the direction favouring the combined treatment arm for most of the scales. After controlling for baseline quality of life and baseline characteristics, only appetite loss and 
digestive symptoms were statistically significant at the $1 \%$ level $(P=0.007$ and $P=0.006$, respectively; Figures $1 \mathrm{~A}$ andB), both in favour of CisGem. Our findings suggest some evidence of treatment differences in favour of CisGem in hepatic function, financial difficulties and satisfaction with health-care scales (Figure 1C, E and F).

There is no evidence of a treatment effect in the difference in mean QoL scores, over all five time points, for any of the QoL responses at the 1\% level (Supplementary Table S2). Responses in the constipation scale showed a difference in the direction favouring the combined treatment arm at a 5\% level $(-6.3,99 \%$ CI: $-13.5-0.9, P=0.02$ ). A difference favouring the CisGem arm was seen in digestive symptoms, global health, social functioning, appetite loss, financial difficulties, insomnia and satisfaction with health-care scales, but our findings do not suggest evidence of a statistical difference (Figure $1 \mathrm{D}$ and $\mathrm{B}$ ).

Long-term survivors. Survival analysis and analysis of baseline characteristics and treatment of patients by grouped length of follow-up is shown in Table 3. A total of 69 (17\%) patients have been followed up for $\leqslant 3$ months, 296 (72\%) patients between 3-24 months and $45(11 \%)$ patients for $>24$ months. Median survival among the 45 long-term survivors is 31.4 months. There is a trend between the following factors and survival time: CisGem treatment, disease status and ECOG performance status $(P<0.001, P=0.028$ and $P<0.001$, respectively). There is a survival advantage for patients receiving CisGem compared with Gem (HR: 0.65, 95\% CI: $0.53-0.79, P<0.001)$, with $17 \%$ of the CisGem patients being followed up for at least 24 months in comparison with $5 \%$ of Gemcitabine-alone patients. Our findings suggest that the higher the ECOG performance status the poorer the survival, and that a performance status of 2 is associated with worst prognosis (ECOG 2, HR: $2.35,95 \%$ CI: $1.68-3.28, P<0.001)$. Locally advanced patients have a better survival prognosis than the patients with metastatic disease (HR 1.34, 95\% CI: $1.07-1.69, P=0.01$ ). A higher percentage of locally advanced patients were followed up for $>24$ months compared with metastatic disease ( $14 \%$ vs $10 \%$, respectively). Our findings did not show evidence that gender, primary tumour site, tumour histology, prior therapy and age were associated with survival.

Long-term primary outcome analysis. With a median follow-up of 9.2 months, 398 (97\%) patients have died as of March 2012 compared to 327 when previously reported (Valle et al, 2010). Of the 12 patients not known to have died, 9 have been followed up for at least 24 months; the other 3 patients were all lost to followup within 6 months of randomisation. As nearly all the patients have died, long-term follow-up can be considered as long-term survival. The median OS was 11.7 months for CisGem and 8.1 months for Gem $(\mathrm{HR}=0.65,95 \% \mathrm{CI}: 0.53-0.79, \quad P<0.001$, Figure 2).

Table 3. Baseline characteristics and treatment of patients, by grouped length of follow-up

\begin{tabular}{|c|c|c|c|c|c|c|c|}
\hline & \multicolumn{3}{|c|}{ Univariate cox model } & \multicolumn{3}{|c|}{ Follow-up period ${ }^{a}$} & \multirow[b]{2}{*}{$\begin{array}{c}P \text {-value } \\
(P \text {-value } \\
\text { for trend })\end{array}$} \\
\hline & $\begin{array}{c}\text { Median } \\
\text { survival } \\
\text { time }(95 \% \mathrm{Cl})\end{array}$ & $\begin{array}{c}\mathrm{HR} \\
(95 \% \mathrm{Cl})\end{array}$ & $P$-value & $\begin{array}{l}0-3 \text { months } \\
(N=69) n(\%)\end{array}$ & $\begin{array}{c}3-24 \text { months } \\
(N=296) n(\%)\end{array}$ & $\begin{array}{c}>24 \text { months } \\
(N=45) n(\%)\end{array}$ & \\
\hline \multicolumn{8}{|l|}{ Treatment } \\
\hline $\begin{array}{l}\text { Gemcitabine alone } \\
\text { Gemcitabine + Cisplatin }\end{array}$ & $\begin{array}{c}8.1(7.0-9.1) \\
11.7(9.6-14.0)\end{array}$ & $\begin{array}{c}1 \\
0.65(0.53-0.79)\end{array}$ & $<0.001$ & $\begin{array}{l}43(21) \\
26(13)\end{array}$ & $\begin{array}{l}152(74) \\
144(71)\end{array}$ & $\begin{array}{l}11(5) \\
34(17)\end{array}$ & $\begin{array}{l}<0.001 \\
(<0.001)\end{array}$ \\
\hline \multicolumn{8}{|l|}{ Gender } \\
\hline $\begin{array}{l}\text { Female } \\
\text { Male }\end{array}$ & $\begin{array}{l}9.6(8.3-11.1) \\
9.1(7.9-11.7)\end{array}$ & $\begin{array}{c}1 \\
1.09(0.90-1.33)\end{array}$ & 0.38 & $\begin{array}{l}35(16) \\
34(18)\end{array}$ & $\begin{array}{l}155(72) \\
141(73)\end{array}$ & $\begin{array}{l}26(12) \\
19(10)\end{array}$ & $\begin{array}{l}0.75 \\
0.5\end{array}$ \\
\hline \multicolumn{8}{|l|}{ Disease status } \\
\hline $\begin{array}{l}\text { Locally advanced disease } \\
\text { Metastatic disease }\end{array}$ & $\begin{array}{r}13.3(8.1-15.0) \\
8.8(8.1-10.0)\end{array}$ & $\begin{array}{c}1 \\
1.34(1.07-1.69)\end{array}$ & 0.01 & $\begin{array}{l}11(11) \\
58(19)\end{array}$ & $\begin{array}{r}78(75) \\
218(71)\end{array}$ & $\begin{array}{l}15(14) \\
30(10)\end{array}$ & $\begin{array}{l}0.086 \\
0.028\end{array}$ \\
\hline \multicolumn{8}{|l|}{ Primary tumour site } \\
\hline $\begin{array}{l}\text { Gallbladder } \\
\text { Bile duct } \\
\text { Ampulla }\end{array}$ & $\begin{array}{r}9.6(8-11.7) \\
8.8(8-10.7) \\
11.8(6.8-14)\end{array}$ & $\begin{array}{c}1 \\
0.96(0.78-1.19) \\
1(0.62-1.62)\end{array}$ & 0.93 & $\begin{array}{c}19(13) \\
50(21) \\
0(0)\end{array}$ & $\begin{array}{r}115(77) \\
163(68) \\
18(90)\end{array}$ & $\begin{array}{r}15(10) \\
28(12) \\
2(10)\end{array}$ & $\begin{array}{l}0.053 \\
0.78\end{array}$ \\
\hline \multicolumn{8}{|l|}{ Tumour histology } \\
\hline $\begin{array}{l}\text { Adenocarcinoma } \\
\text { Other }\end{array}$ & $\begin{array}{l}9.6(8.3-11.1) \\
7.2(4.5-10.8)\end{array}$ & $\begin{array}{c}1 \\
1.27(0.88-1.82)\end{array}$ & 0.21 & $\begin{array}{r}61(16) \\
8(24)\end{array}$ & $\begin{array}{r}273(72) \\
23(70)\end{array}$ & $\begin{array}{c}43(11) \\
2(6)\end{array}$ & $\begin{array}{l}0.37 \\
0.16\end{array}$ \\
\hline \multicolumn{8}{|c|}{ ECOG performance status } \\
\hline $\begin{array}{l}0 \\
1 \\
2\end{array}$ & $\begin{array}{c}11.9(9.7-14.3) \\
9.3(7.9-11) \\
5.7(3.4-7.1)\end{array}$ & $\begin{array}{c}1 \\
1.29(1.04-1.61) \\
2.35(1.68-3.28)\end{array}$ & $<0.001$ & $\begin{array}{l}11(8) \\
42(18) \\
16(31)\end{array}$ & $\begin{array}{r}98(75) \\
163(71) \\
35(67)\end{array}$ & $\begin{array}{c}21(16) \\
23(10) \\
1(2)\end{array}$ & $\begin{array}{r}0.001 \\
(<0.001)\end{array}$ \\
\hline \multicolumn{8}{|l|}{ Prior therapy } \\
\hline $\begin{array}{l}\text { None } \\
\text { Any prior therapy }\end{array}$ & $\begin{array}{l}8.0(6.8-10.1) \\
9.8(8.7-11.6)\end{array}$ & $\begin{array}{c}1 \\
1.03(0.82-1.30)\end{array}$ & 0.79 & $\begin{array}{l}20(20) \\
49(16)\end{array}$ & $\begin{array}{r}66(66) \\
230(74)\end{array}$ & $\begin{array}{l}14(14) \\
31(10)\end{array}$ & $\begin{array}{l}0.27 \\
0.94\end{array}$ \\
\hline \multicolumn{8}{|l|}{ Age (years) } \\
\hline $\begin{array}{l}23-60 \\
60-70 \\
70-84\end{array}$ & $\begin{array}{l}9.3(8-12.2) \\
9.7(7.9-11.8) \\
9.1(7-10.7)\end{array}$ & $\begin{array}{c}1 \\
1(0.80-1.25) \\
1.13(0.86-1.48)\end{array}$ & 0.61 & $\begin{array}{l}22(15) \\
32(18) \\
15(17)\end{array}$ & $\begin{array}{r}111(75) \\
118(67) \\
67(77)\end{array}$ & $\begin{array}{l}15(10) \\
25(14) \\
5(6)\end{array}$ & $\begin{array}{l}0.23 \\
0.41\end{array}$ \\
\hline \multicolumn{8}{|c|}{ 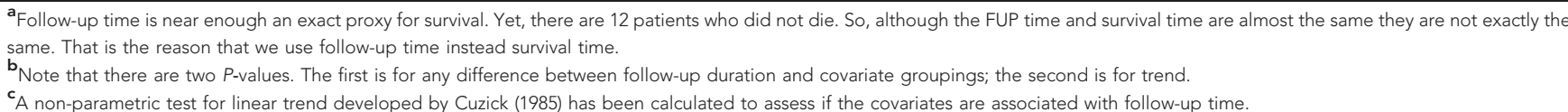 } \\
\hline
\end{tabular}




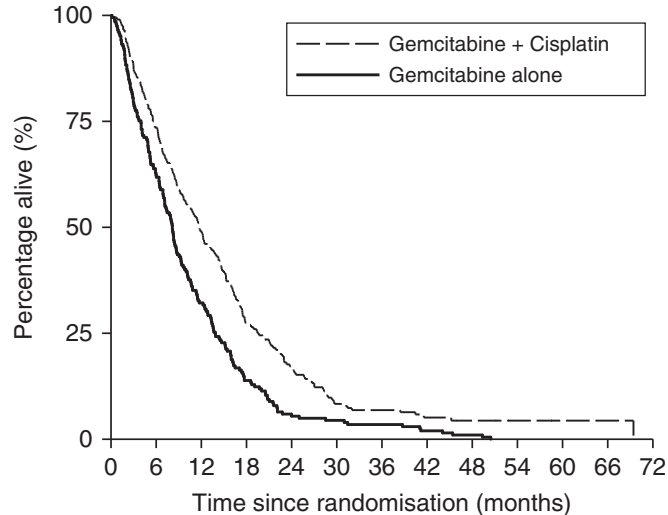

Number at risk

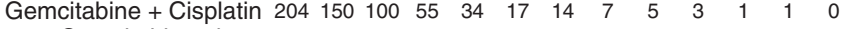
Gemcitabine alone $\begin{array}{lllllllllllll}206 & 126 & 65 & 28 & 11 & 9 & 7 & 4 & 2 & 0 & 0 & 0 & 0\end{array}$

Figure 2. Kaplan-Meier long-term overall survival by treatment arm.

\section{DISCUSSION}

Although ABC-02 has defined the standard of care for BTC patients, the survival benefit is modest and most patients do not survive beyond a year. QoL is therefore pivotal to globally evaluate this benefit, particularly in the context of a disease with multiple symptoms that can often be difficult to manage. Our data demonstrate that QoL is not adversely affected despite a modest non-significant increase in some toxicities such as neutropenia.

Research on QoL in ABC is challenging. Assessing the QoL of $\mathrm{ABC}$ patients is critically important in a population who are often unwell from both local (obstructive jaundice, biliary sepsis, bowel obstruction and liver pain) and systemic consequences (malaise, fatigue and depression) of advanced disease. This is the likely reason for missing data (20\% at baseline and 59\% at 12 weeks) reflecting a common problem of QoL studies in unwell cancer patients. Extant data reflect both a lack of appropriate instruments and study compliance realities. Heffernan et al (2002) described the FACT-G scale for hepatobiliary malignancies, but to date it has been used only in pancreas cancer studies with no survival benefit (Rocha Lima et al, 2004; Moinpour et al, 2010). EORTC QoL scales have been described for liver metastasis (LMC21) (Kavadas et al, 2003) and pancreas (PAN26) (Fitzsimmons et al, 1999), the latter used here, but are limited by not being BTC specific. It is likely that a recently validated BTC instrument will be used for BTC in the future (EORTC QLQ-BIL21; Friend et al, 2011). This is a mostly a combination of PAN26 and LMC21 and requires phase 4 evaluation across multiple ethnic groups before general adoption. Limitations of our data include the missing data (Table 1; Supplementary Table S1) and the assumption that that these data are balanced between the treatment arms. Nevertheless, these are the only data describing QoL in the context of a treatment-defining study for $\mathrm{ABC}$ and as such set the standard for subsequent investigation.

The majority of long-term outcomes are described in surgical series and there are no published data for the long-term survival of patients presenting with advanced disease. These data describe a cohort of long-term survivors and are consistent with an increasing appreciation that $\mathrm{ABC}$ are sensitive to chemotherapy (Eckel et al, 2011). Ongoing studies in second and subsequent line therapies will continue to build a therapeutic hierarchy for $\mathrm{ABC}$, such as the UK National Cancer Research Institute ABC-06 study (Lamarca et al, 2014). The added efficacy of Cisplatin to gemcitabine across multiple variables including primary tumour site (bile duct, gall bladder and ampulla) is confirmed, suggesting that although they may be molecularly heterogeneous (Jiao et al, 2013) their sensitivity to cisplatin is similar.

\section{CONCLUSION}

The survival benefit of CisGem compared to Gem in ABC is not paralleled by a benefit in QoL. A qualitative description of longterm survivors and the long-term primary outcome analysis supports the survival benefit. We recommend that CisGem remains the standard of care for $\mathrm{ABC}$.

\section{ACKNOWLEDGEMENTS}

We thank all participating patients and their families without whom these clinical studies would not have been possible. This work was supported by the following: ABC-02 was an investigatorinitiated study sponsored by UCL Clinical Trials Unit, funded by Cancer Research UK with gemcitabine provided by Lilly Oncology (unrestricted grant). JB is partly supported by the UCLH/UCL Biomedical Research Centre. AL is supported by a CRUK grant C444/A15953 to the UCL CRUK trials centre.

\section{CONFLICT OF INTEREST}

The authors declare no conflict of interest.

\section{REFERENCES}

Aaronson NK, Ahmedzai S, Bergman B, Bullinger M, Cull A, Duez NJ, Filiberti A, Flechtner H, Fleishman SB, Haes J. C. J. M. D., Kaasa S, Klee M, Osoba D, Razavi D, Rofe PB, Schraub S, Sneeuw K, Sullivan M, Takeda F (1993) The European Organization for Research and Treatment of Cancer QLQ-C30: A quality-of-life instrument for use in International Clinical Trials in Oncology. J Natl Cancer Inst 85: 365-376.

Cuzick J (1985) A Wilcoxon-type test for trend. Stat Med 4(1): 87-90.

de Groen PC, Gores GJ, Larusso NF, Gunderson LL, Nagorney DM (1999) Biliary tract cancers. N Engl J Med 341: 1368-1378.

Eckel F, Brunner T, Jelic S. ESMO Guidelines Working Group (2011) Biliary cancer: ESMO Clinical Practice Guidelines for diagnosis, treatment and follow-up. Ann Oncol 22: vi40-vi44.

Fitzsimmons D, Johnson CD, George S, Payne S, Sandberg AA, Bassi C, Beger HG, Birk D, Büchler MW, Dervenis C, Fernandez Cruz L, Friess H, Grahm AL, Jeekel J, Laugier R, Meyer D, Singer MW, Tihanyi T (1999) Development of a disease specific quality of life (QoL) questionnaire module to supplement the EORTC core cancer QoL questionnaire, the QLQ-C30 in patients with pancreatic cancer. Eur J Cancer 35: 939-941.

Friend E, Yadegarfar G, Byrne C, Johnson CD, Sezer O, Pucciarelli S, Pereira SP, Chie WC, Banfield A, Ramage JK (2011) Development of a questionnaire (EORTC module) to measure quality of life in patients with cholangiocarcinoma and gallbladder cancer, the EORTC QLQ-BIL21. Br J Cancer 104: 587-592.

Heffernan N, Cella D, Webster K, Odom L, Martone M, Passik S, Bookbinder M, Fong Y, Jarnagin W, Blumgart L (2002) Measuring health-related quality of life in patients with hepatobiliary cancers: the functional assessment of cancer therapy-hepatobiliary questionnaire. J Clin Oncol 20: 2229-2239.

Jiao Y, Pawlik TM, Anders RA, Selaru FM, Streppel MM, Lucas DJ, Niknafs N, Guthrie VB, Maitra A, Argani P, Offerhaus GJA, Roa JC, Roberts LR, Gores GJ, Popescu I, Alexandrescu ST, Dima S, Fassan M, Simbolo M, Mafficini A, Capelli P, Lawlor RT, Ruzzenente A, Guglielmi A, Tortora G, de Braud F, Scarpa A, Jarnagin W, Klimstra D, Karchin R, Velculescu VE, Hruban RH, Vogelstein B, Kinzler KW, Papadopoulos N, Wood LD (2013) Exome sequencing identifies frequent inactivating mutations in BAP1, ARID1A and PBRM1 in intrahepatic cholangiocarcinomas. Nat Genet 45: 1470-1473. 
Kavadas V, Blazeby JM, Conroy T, Sezer O, Holzner B, Koller M, Buckels J (2003) Development of an EORTC disease-specific quality of life questionnaire for use in patients with liver metastases from colorectal cancer. Eur J Cancer 39: 1259-1263.

Lamarca A, Palmer D, Wasan H, Ryder WD, Davies L, Flight H, Rogan J, Hubner R, Bridgewater JA, Valle JW (2014) 748TiPABC-06: a randomised phase III, multi-centre, open-label study of active symptom control (ASC) alone or ASC with oxaliplatin / 5-FU chemotherapy for patients with locally advanced / metastatic biliary tract cancers (ABC) previously treated with cisplatin / gemcitabine chemotherapy. Ann Oncol 25: iv252.

Moinpour CM, Vaught NL, Goldman B, Redman MW, Philip PA, Millwood B, Lippman SM, Seay TE, Flynn PJ, O’Reilly EM, Rowland KM, Wong RP, Benedetti J, Blanke CD (2010) Pain and emotional well-being outcomes in Southwest Oncology Group-Directed Intergroup Trial S0205: a phase III study comparing gemcitabine plus cetuximab versus gemcitabine as first-line therapy in patients with advanced pancreas cancer. J Clin Oncol 28: 3611-3616.

Okusaka T, Nakachi K, Fukutomi A, Mizuno N, Ohkawa S, Funakoshi A, Nagino M, Kondo S, Nagaoka S, Funai J, Koshiji M, Nambu Y, Furuse J, Miyazaki M, Nimura Y (2010) Gemcitabine alone or in combination with cisplatin in patients with biliary tract cancer: a comparative multicentre study in Japan. Br J Cancer 103: 469-474.

Rocha Lima CM, Green MR, Rotche R, Miller WH, Jeffrey GM, Cisar LA, Morganti A, Orlando N, Gruia G, Miller LL (2004) Irinotecan plus gemcitabine results in no survival advantage compared with gemcitabine monotherapy in patients with locally advanced or metastatic pancreatic cancer despite increased tumor response rate. J Clin Oncol 22: 3776-3783.

Sloan JA, Zhao X, Novotny PJ, Wampfler J, Garces Y, Clark MM, Yang P (2012) Relationship between deficits in overall quality of life and non-small-cell lung cancer survival. J Clin Oncol 30: 1498-1504.

Valle J, Wasan H, Palmer DH, Cunningham D, Anthoney A, Maraveyas A, Madhusudan S, Iveson T, Hughes S, Pereira SP, Roughton M, Bridgewater J. The Abc-02 Trial Investigators (2010) Cisplatin plus gemcitabine versus gemcitabine for biliary tract cancer. N Engl J Med 362: 1273-1281.

Valle JW, Furuse J, Jitlal M, Beare S, Mizuno N, Wasan H, Bridgewater J, Okusaka T (2013) Cisplatin and gemcitabine for advanced biliary tract cancer: a meta-analysis of two randomised trials. Ann Oncol 25: 391-398.

Valle JW, Wasan H, Johnson P, Jones E, Dixon L, Swindell R, Baka S, Maraveyas A, Corrie P, Falk S, Gollins S, Lofts F, Evans L, Meyer T, Anthoney A, Iveson T, Highley M, Osborne R, Bridgewater J (2009) Gemcitabine alone or in combination with cisplatin in patients with advanced or metastatic cholangiocarcinomas or other biliary tract tumours: a multicentre randomised phase II study-The UK ABC-01 Study. Br J Cancer 101: 621-627.

This work is published under the standard license to publish agreement. After 12 months the work will become freely available and the license terms will switch to a Creative Commons AttributionNonCommercial-Share Alike 4.0 Unported License.

Supplementary Information accompanies this paper on British Journal of Cancer website (http://www.nature.com/bjc) 